\title{
Dynamic Response Characteristics of Roadway Surrounding Rock under Strong Seismic Disturbance
}

\author{
Wu Quanlin ${ }^{1}$, Wu Quansen ${ }^{2, *}$, Jiang Jinquan ${ }^{2}$, Li Wenting' ${ }^{1}$ and Wang Wei ${ }^{3}$ \\ ${ }^{1}$ Security Engineering Technology Center, Ji ning University, Qu fu 273155, China \\ ${ }^{2}$ State Key Laboratory of Mining Disaster Prevention and Control Co-founded by Shandong Province and Ministry of Science \\ and Technology, Shandong University of Science and Technology, Tai an 271002, China \\ ${ }^{3}$ Department of Metallurgy and Mineral Processing University of Zambia, P.O.Box 32379 Lusaka, Zambia
}

Received 1 December 2016; Accepted 26 February 2017

\begin{abstract}
The fracture and movement of hard thick strata, particularly super thick hard key stratum, can induce strong mine seismicity. The disturbance caused by mine seismicity can directly influence the stability of a roadway. To address this problem, the numerical simulation software $\mathrm{FLAC}^{2 \mathrm{D}}$ was used to simulate strong seismicity by applying strong stress waves on the bottom of hard thick strata. The stress, displacement, and plastic zone data of roadway surrounding rock were extracted. The dynamic response laws of roadway surrounding rock under the disturbance were investigated. The influence of boundary condition on the dynamic response of the roadway was studied simultaneously. Result indicates that the increase in horizontal stress of the roof and vertical stress of the ribs result in the spallation damage of the roof and the compression of the coal ribs under seismic influence. The convergence of the ribs is greater than that of the roof and the floor, and rock bursts can easily occur in the ribs of the roadway. The significant influencing time for the ground displacement of the roadway is $0.6 \mathrm{~s}$. The convergence of two ribs of the gob-side roadway is 9.27 times as high as that of the solid-coal roadway. The results are verified via a case study. The conclusions obtained in this study provide a theoretical basis for the design of a roadway support on hard thick rock strata, which is significant to the safety of the working face.
\end{abstract}

Keywords: Strong seismicity, Mining roadway, Stress response, Surrounding rock deformation, Rock burst danger

\section{Introduction}

Coal is the main energy source in China[1]. With the increasing energy demands, the intensity of coal mining increases, and mining geological conditions and dynamic disasters become more complicated and serious, particularly when the working face is covered by tens or even hundreds of meters of hard thick strata. A large suspension area will appear under a hard-thick stratum after mining the working face, which can induce strong dynamic phenomena, including mine seismicity, rock burst, support break off, water in bed separation, and gas inrush. These phenomena can seriously threaten the safety of production because of the special properties of hard thick strata, including high strength, good integrity, and large initial breaking span. At present, hard thick strata have been found in high positions in many coal mines in China, which result in strong dynamic disasters occurring during the mining process. The production practice indicates that the fracture of hard thick strata can induce mine seismicity, which can generate different degrees of shock waves that can lead to dynamic disasters, such as rock burst, coal outburst, and gas outburst[2-6]. The fracture of a super thick hard key stratum can induce strong mine seismicity, which can seriously harm a wide range of roadways and working faces[7-11]. The correct understanding of the effect of strong seismicity on a

- E-mail address: 2401392747@qq.com

ISSN: 1791-2377 C 2017 Eastern Macedonia and Thrace Institute of Technology. All rights reserved. roadway is critical for maintenance and safe production. However, determining the effect of strong seismicity on a roadway via field measurement is difficult due to the short period of a strong seismic action. Thus, this study focused on the occurrence of huge thick magmatic rocks on the roof. The mechanical response of roadway surrounding rock under the strong seismicity caused by the highly positioned magmatic rocks were simulated and analyzed using the numerical simulation software FLAC ${ }^{2 \mathrm{D}}$. The change laws of the stress field, displacement field, and plastic zone of the roadway under different boundary conditions were studied.

\section{State of the art}

The dynamic disturbance effect of the overlying strata on the stability of roadway surrounding rock has captured the attention of many scholars, who conducted relevant studies. Real-time microseismic signals can be collected using microseismic monitoring technology, thereby providing the basis for the dynamic response analysis of a gateway. Baumgardt D.R. summarized the relationship between the occurrence of a rock burst and the degree of a rock burst in a mine in the United States. In this previous study, detailed information about the blast, including the type and depth of mining operation and the blasting delay pattern, was reviewed and combined with a seismological analysis of the event[12]. At present, numerical modeling is a state-of-theart technique that is widely used in rock mechanics study[13-14]. Song Xi-Xian analyzed the effective rule of 
the side pressure coefficient for the stress distribution of a gateway surrounding rock under static and dynamic loads by using the numerical simulation software RFPA; the influencing law of confining pressure on the destruction form of roadway surrounding rock was obtained. This previous study indicated that the lateral pressure coefficient $\lambda$ played a decisive role in the stress field distribution of roadway surrounding rock under static and dynamic disturbances[15]. Hu Shao-Bin used the numerical simulation software LS-DYNA to analyze the stability and energy change rule of a coal and rock roadway system under stress wave disturbance with different frequencies and amplitudes; the amplitude and frequency response characteristics of the dynamic disturbance were obtained in the simulation. This previous study found that the distance from the maximum reflection energy flow density peak position to the free surface, as well as the perturbation frequency, conformed to a power function relation[16]. Abdul-Wahed M.K. selected the Provence mine as research object and used the combined methods of microseismic monitoring and numerical modeling to effectively predict the rock burst danger zone. This previous study showed that such a coupling could be an efficient approach for detecting areas subjected to rock burst hazards[17]. Jikun Liu studied the spectral characteristics of microseismic signals in coal rupture; this researcher determined that such signals increased with the increase in compressive stress during early coal rupture period and a huge amount of microseismic signals was destroyed before the coal body. This previous study demonstrated the advantage of applying a HilbertHuang transform, which could extract the main features of signals[18]. Hosseini N. studied the law of stress redistribution in longwall mining. The results showed that the state of stress redistribution around the longwall panel could be deduced from the velocity images[19]. Chen GuoXiang studied the response characteristics of the stress and plastic zones of roadway surrounding rock under different disturbances by using the numerical simulation software FLAC $^{2 \mathrm{D}}$ and obtained the influencing law for rock burst hazard on roadway sides. This previous study found that the maximum vertical and horizontal stresses of the inner coal wall increased more rapidly than the outer coal wall[20]. Lu Ai-Hong simulated and analyzed the fracture process of roadway surrounding rock under stress waves by using the numerical calculation software LS-DYNA. The characteristics of the formation and scope of the spallation structure under the given intensity condition of stress waves were obtained. The numerical simulation showed that the formation of layer cracks and failure structures is closely related to roadway depth $H$ [21].

The aforementioned studies analyzed the influencing law for disturbance on the stability of roadway surrounding rock in terms of disturbance form, side pressure coefficient, and discontinuity surface; however, the stability of roadway surrounding rock under different boundary conditions was not considered. When super thick hard magmatic rocks exist in the highstand of a working face, the suspension roof area is large during the mining process. The large-scale migration of the broken key stratum can easily induce strong mine seismicity, which can damage the roadway and the working face.

The remainder of this paper is organized as follows. Section 3 proposes the engineering background of a highstand magmatic rock and presents the numerical calculation model and related parameters. Section 4 analyzes the dynamic response of a mining roadway under strong seismicity and verifies the results through case studies. Section 5 summarizes the conclusions.

\section{Methodology}

A $44 \mathrm{~m}$ hard thick magmatic rock exists above mining area 104 in Yangliu Coal Mine in China. Mine seismicity occurs frequently under the influence of mining, which threatens the safety of the coal mining face and affect the stability of the roadway. The degree of effect increases with the increase in mine seismicity energy. The 10416 working face of Huaibei Yangliu Coal Mine is used as an example to study the dynamic response characteristics of gateway surrounding rock under strong seismic disturbance.

\subsection{Engineering background}

The 10416 working face is located in mine section 104. In the northeast, 106 is a coal mining entity; in the southwest, 10414 is a working face gob. The width of the mine section protective coal pillar is $5 \mathrm{~m}$, as shown in Fig. 1. The south limb (open-off cut side) is bounded by the Xiaoshenjia fault pillar, whereas the north limb (stopping line side) is bounded by the east limb main roadway protection pillar. The working face mines coal seam no. 10 of the Shanxi Formation, which has an inclined length of $180 \mathrm{~m}$ and a strike length of $1160 \mathrm{~m}$. Coal seam no. 10 is buried at a depth between $-570 \mathrm{~m}$ and $-610 \mathrm{~m}$, and has a simple structure. The average thickness is $3.2 \mathrm{~m}$ and the average angle is $4^{\circ}$. The mine is temporarily identified as a high-gas mine because of the high local gas emission. Approximately 17 faults occur in the working face, the largest fault throw is $10 \mathrm{~m}$. The upper and lower roadways are supported by a combination of bolts, beams, meshes, and bolt cables. The material of the bolt body is ultra-strong sinisterly thread steel. The specification of the roof bolts is $\Phi 20 \mathrm{~mm} \times 2500 \mathrm{~mm}$, whereas that of the roadway bolts is $\Phi 20 \mathrm{~mm} \times 2200 \mathrm{~mm}$; the strain row spacing is $800 \mathrm{~mm}$. The specification of the material of the bolt cables is $\Phi 17.8 \mathrm{~mm} \times 6300 \mathrm{~mm}$ steel strand, and the row spacing is $4000 \mathrm{~mm}$.

Two layers of magmatic rocks are developed above 10416 working face, and bedding invasion occurs along coal seam no. $5_{2}$ roof and coal seam no. $7_{2}$ roof. The average thickness of the magmatic rock of coal seam no. $5_{2}$ roof is $31.5 \mathrm{~m}$, with an average distance of $163.1 \mathrm{~m}$ to coal seam no. 10. The average thickness of the magmatic rock of coal seam no. $7_{2}$ roof is $43.5 \mathrm{~m}$, with an average distance of $104.1 \mathrm{~m}$ to coal seam no.10. From the results of the rock mechanics test conducted by ground drilling core, the magmatic rocks exhibit high intensity, a unidirectional compressive strength of 113.6 MPa, and a tensile strength of $25 \mathrm{MPa}$. 


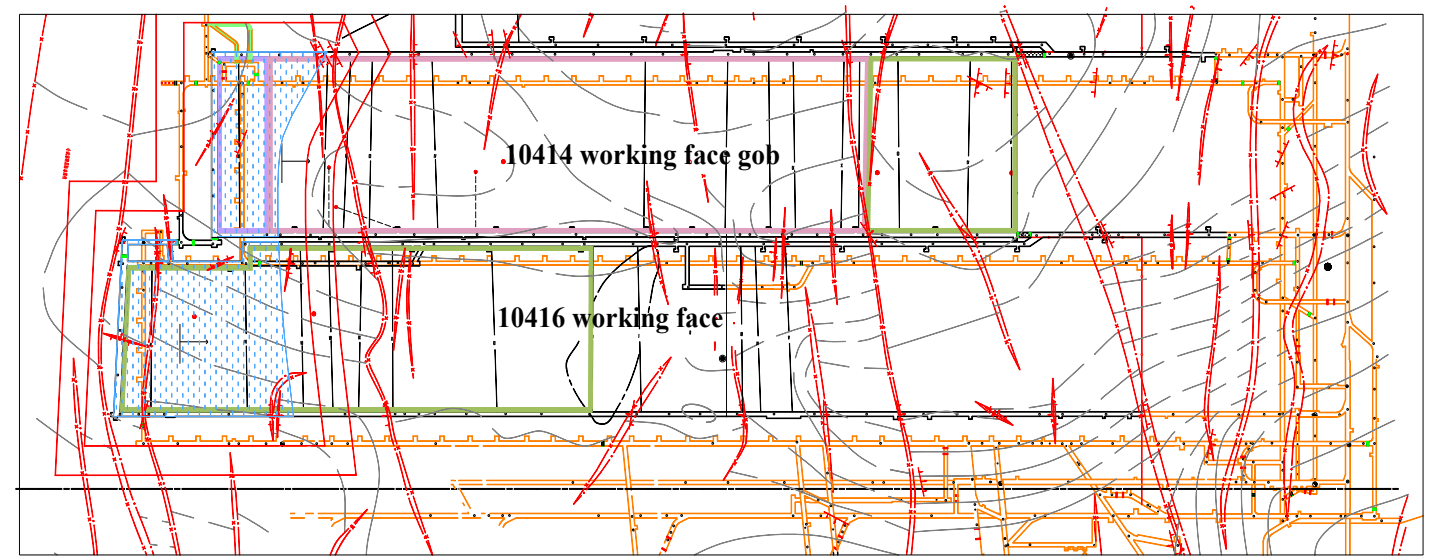

Fig. 1. Layout of 10416 working face

\subsection{Numerical calculation model}

The numerical calculation model was built based on the geological engineering condition of 10416 working face in Yangliu Coal Mine using the numerical simulation software FLAC $^{2 \mathrm{D}}$. The dynamic response characteristics of the surrounding rock under strong disturbance and different boundary conditions were studied through the analysis of dynamic modules. The size of the model is $660 \mathrm{~m}$ (length) $\times$ $208 \mathrm{~m}$ (height), with a roadway of $5 \mathrm{~m}$ (width) $\times 3 \mathrm{~m}$ (height), thereby simulating a coal seam depth of $600 \mathrm{~m}$. A vertical uniformly distributed load of $10.75 \mathrm{MPa}$ is applied on top of the model. The parameters of the mechanics and the strata of the model are presented in Table 1.

Table 1. Parameters of mechanics and strata of model

\begin{tabular}{|c|c|c|c|c|c|c|c|}
\hline Lithology & Thickness/m & $\begin{array}{l}\text { Density } \\
/\left(\mathbf{k g} / \mathbf{m}^{3}\right)\end{array}$ & $\begin{array}{c}\text { Bulk } \\
\text { modulus } \\
/ \text { MPa }\end{array}$ & $\begin{array}{c}\text { Shear } \\
\text { modulus } \\
/ \text { MPa }\end{array}$ & $\begin{array}{c}\text { Cohesion } \\
\text { /MPa }\end{array}$ & $\begin{array}{c}\text { Tensile } \\
\text { Strength /MPa }\end{array}$ & $\begin{array}{c}\text { Friction } \\
\text { angle } \\
/^{\circ}\end{array}$ \\
\hline Packsand & 20 & 2530 & $13.4 \times 10^{3}$ & $7.6 \times 10^{3}$ & 1.4 & 2.78 & 37 \\
\hline Mudstone & 2 & 2340 & $9.8 \times 10^{3}$ & $7.1 \times 10^{3}$ & 0.5 & 1.55 & 39 \\
\hline Siltstone & 4 & 2530 & $13.4 \times 10^{3}$ & $7.6 \times 10^{3}$ & 1.4 & 1.85 & 37 \\
\hline Gritrock & 2 & 2540 & $14.7 \times 10^{3}$ & $8.1 \times 10^{3}$ & 10 & 2.8 & 26 \\
\hline Mudstone & 3 & 2340 & $9.8 \times 10^{3}$ & $7.1 \times 10^{3}$ & 0.5 & 1.55 & 39 \\
\hline Gritrock & 1 & 2540 & $14.7 \times 10^{3}$ & $8.1 \times 10^{3}$ & 10 & 2.8 & 26 \\
\hline Magmatic rock & 44 & 3000 & $75 \times 10^{3}$ & $47 \times 10^{3}$ & 2.2 & 25 & 45 \\
\hline $7_{2}$ Coal & 1 & 1350 & $10.5 \times 10^{3}$ & $6.5 \times 10^{3}$ & 1.2 & 0.9 & 23 \\
\hline Siltstone & 2 & 2530 & $13.4 \times 10^{3}$ & $7.6 \times 10^{3}$ & 1.4 & 1.85 & 37 \\
\hline Gritrock & 7 & 2540 & $14.7 \times 10^{3}$ & $8.1 \times 10^{3}$ & 10 & 2.8 & 26 \\
\hline Siltstone & 2 & 2530 & $13.4 \times 10^{3}$ & $7.6 \times 10^{3}$ & 1.4 & 1.85 & 37 \\
\hline Mudstone & 3 & 2340 & $9.8 \times 10^{3}$ & $7.1 \times 10^{3}$ & 0.5 & 1.55 & 39 \\
\hline $8_{2}$ Coal & 2 & 1350 & $10.5 \times 10^{3}$ & $6.5 \times 10^{3}$ & 1.2 & 0.9 & 23 \\
\hline Mudstone & 3 & 2340 & $9.8 \times 10^{3}$ & $7.1 \times 10^{3}$ & 0.5 & 1.55 & 39 \\
\hline Siltstone & 3 & 2530 & $13.4 \times 10^{3}$ & $7.6 \times 10^{3}$ & 1.4 & 1.85 & 37 \\
\hline Mudstone & 13 & 2340 & $9.8 \times 10^{3}$ & $7.1 \times 10^{3}$ & 0.5 & 1.55 & 39 \\
\hline Gritrock & 4 & 2540 & $14.7 \times 10^{3}$ & $8.1 \times 10^{3}$ & 10 & 2.8 & 26 \\
\hline Mudstone & 4 & 2340 & $9.8 \times 10^{3}$ & $7.1 \times 10^{3}$ & 0.5 & 1.55 & 39 \\
\hline Siltstone & 2 & 2530 & $13.4 \times 10^{3}$ & $7.6 \times 10^{3}$ & 1.4 & 1.85 & 37 \\
\hline Mudstone & 49 & 2340 & $9.8 \times 10^{3}$ & $7.1 \times 10^{3}$ & 0.5 & 1.55 & 39 \\
\hline Packsand & 5 & 2530 & $13.4 \times 10^{3}$ & $7.6 \times 10^{3}$ & 1.4 & 2.78 & 37 \\
\hline Mudstone & 3 & 2340 & $9.8 \times 10^{3}$ & $7.1 \times 10^{3}$ & 0.5 & 1.55 & 39 \\
\hline 10 Coal & 3 & 1350 & $10.5 \times 10^{3}$ & $6.5 \times 10^{3}$ & 1.2 & 0.9 & 23 \\
\hline Gritrock & 26 & 2540 & $14.7 \times 10^{3}$ & $8.1 \times 10^{3}$ & 10 & 2.8 & 26 \\
\hline
\end{tabular}

\subsection{Modeling scheme}

This study focused on shear stress wave, which was applied to the gob side at the bottom of the magmatic rocks. The strong mining seismicity source selected the distance $M_{0}$ was $1.0 \times 10^{13} \mathrm{~N} \cdot \mathrm{m}$. and dominant frequency $f_{0}$ was $50 \mathrm{~Hz}$. The power operation time was set as $1.0 \mathrm{~s}$. A static boundary and Rayleigh damping were adopted in the model. Meanwhile, the model used plane strain analysis, whose criterion was Mohr-Coulomb strength[22-23]. Gobs and working face roadways were simulated with an empty element. The model diagram is shown in Fig. 2.

To analyze the response characteristics of mining roadway surrounding rock under a dynamic disturbance, monitoring points, which were used to monitor change in stress and displacement, were set on the roof, floor, and two sides of the roadway. The simulation processes were as follows. 1) A uniformly distributed load is exerted on top of the model to obtain the original rock stress field. 2) The right 
side of the working face is excavated, and stress balance is calculated. 3) The roadway is excavated, and stress balance is calculated. 4) A disturbance is exerted on the bottom of the magmatic rocks in the model, and the dynamic calculation time is set as $1 \mathrm{~s}$.

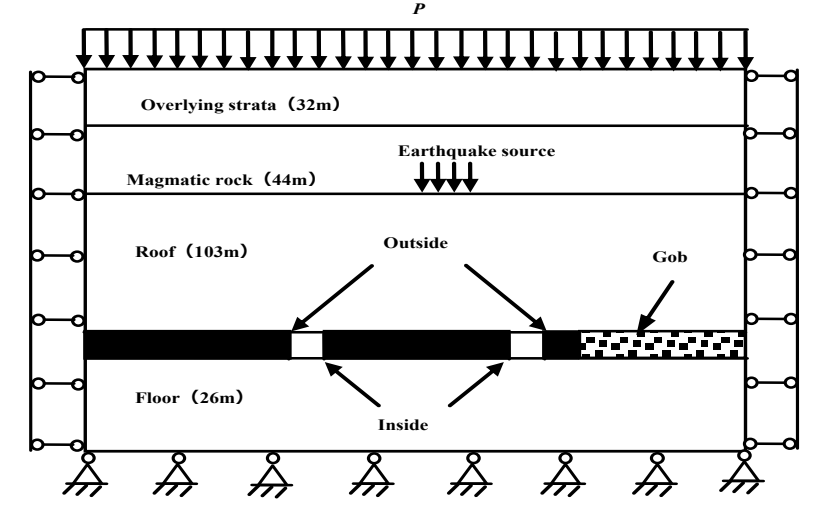

Fig. 2. Model of numerical simulation

\section{Result analysis and discussion}

The stability of the roadway surrounding rock is affected by the overlying strong seismicity, which leads to the displacement of the roadway. Moreover, the stress state of the surrounding rock is changed, which differs from the boundary condition of the roadway.

\subsection{Stress disturbance response analysis of the roadway surrounding rock}

Four displacement monitoring points, labeled A, B, C, and D, were set at the midpoints of the roof, floor, and two sides of the solid-coal roadway surrounding rock and gob-side roadway surrounding rock, respectively. The side coal walls between the two mining roadways of the same working face are referred to as the inside, whereas the coal walls at the other side are referred to as the outside.) Four stress monitoring points, namely $1^{\#}, 2^{\#}, 3^{\#}$, and $4^{\#}$, were set $2 \mathrm{~m}$ outside of the displacement monitoring points, as shown in Fig. 3. The monitored dynamic response rules for the roof, floor, and two sides are shown in Figs. 4 and 5.

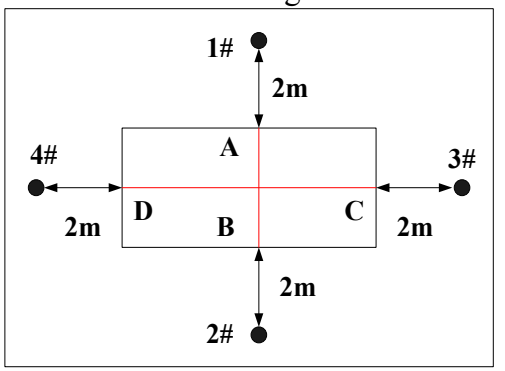

Fig. 3. Schematic of the arrangement of monitoring points

As shown in Fig. 4, for the solid-coal roadway, the influence of the aforementioned mine seismic disturbance on the stress of the roadway surrounding rock is mainly reflected as roof horizontal stress and inside vertical stress. As shown in Fig. 4(a), when the influencing time of the mine was $0.15 \mathrm{~s}$, roof horizontal stress instantly reached the maximum value of $21.52 \mathrm{MPa}$, disturbance amplitude was reduced in the next $0.5 \mathrm{~s}$, and horizontal stress fluctuated around 9-16 $\mathrm{MPa}$. Therefore, the roof strata were prone to becoming loose and dislocating because of shear failure under seismic disturbance of the mine, which would result in bolt breakage and support failure. The horizontal stress levels of the two sides and the floor were less affected by mine seismicity. Horizontal stress changes exhibited an entirely different trend compared with that of the roof. Stress level was low, and a steady state was basically reached after a disturbance of $0.4 \mathrm{~s}$.

As shown in Fig. 4(b), the vertical stress levels of the two sides were significantly higher than those of the roof and the floor. Moreover, the vertical stress level of the inside was higher than that of the outside.

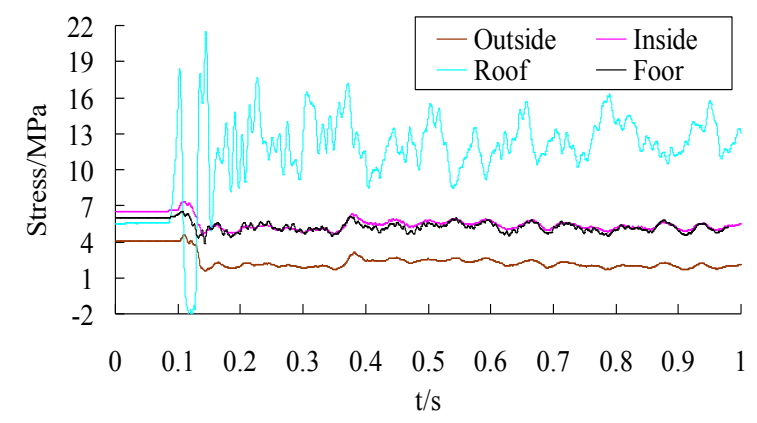

(a) Horizontal stress

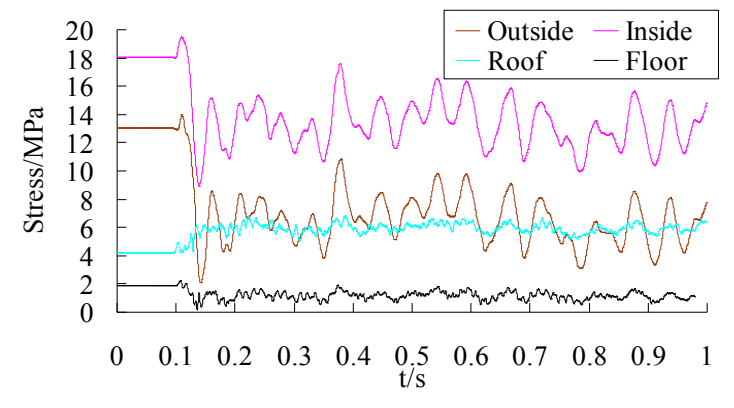

(b) Vertical stress

Fig. 4. Stress response curve of the solid-coal roadway surrounding rock

When the influencing time of mine seismicity was $0.11 \mathrm{~s}$, the inside vertical stress reached a maximum value of 19.18 $\mathrm{MPa}$, thereby resulting in a sharp compression of the inside. Then, the vertical stress of the coal wall was reduced rapidly, and the deformation of the coal mass rebound. The risk of rock burst would increase significantly in the process of coal mass compression-rebound, which might easily cause sudden stability failure of the roadway. Vertical stress amplitude was reduced after a disturbance of $0.4 \mathrm{~s}$, and vertical stress fluctuated at approximately 10-16 MPa. The trend of the outside vertical stress was similar to that of the inside; however, the value decreased markedly. The vertical stress levels of the roof and the floor were low, and they basically reached a steady state after a disturbance of $0.4 \mathrm{~s}$.

Therefore, the dynamic response characteristics of the surrounding rock under seismic disturbance of the mine differed from those of the roof, floor, and two sides of the solid-coal roadway. Stability failure is prone to occur in the roof and the inside of the roadway.

As shown in Fig. 5, for the gob-side roadway, the influence of the aforementioned mine seismic disturbance on the stress of the roadway surrounding rock is mainly reflected as roof horizontal stress and outside vertical stress. Under the dual influence of gob-side abutment pressure and mine seismic disturbance, the stress level of the gob-side roadway was generally significantly higher than that of the solid-coal roadway. 


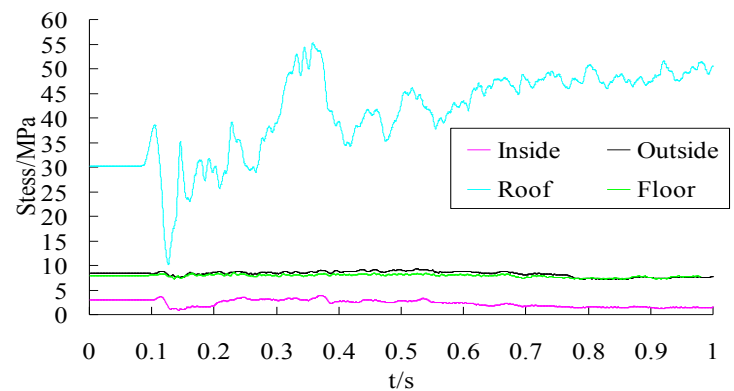

(a) Horizontal stress

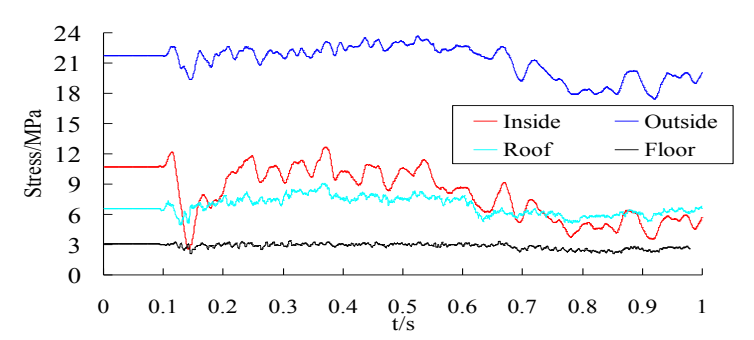

(b) Vertical stress

Fig. 5. Stress response curve of the gob-side roadway surrounding rock

As shown in Fig. 5(a), the horizontal stress of the gob-side roadway roof was at a high level, and it reached a maximum value of $55.28 \mathrm{MPa}$, which was 2.57 times that on the solidcoal roadway roof after a disturbance of $0.36 \mathrm{~s}$, and then it decreased. However, it continuously increased when mine seismicity lasted for $0.56 \mathrm{~s}$. Therefore, the risks of shear failure and bolt breakage for the gob-side roadway were higher than those for the solid-coal roadway.

As shown in Fig. 5(b), the vertical stress level of the outside was higher than that of the inside. However, the vertical stress of the outside changed gradually compared with that of the inside. It fluctuated at approximately 17.6923.35 $\mathrm{MPa}$, and reached its maximum value when mine seismicity lasted for $0.53 \mathrm{~s}$.

The mechanical responses of different parts of the roadway surrounding rock under dynamic disturbances significantly differed from those shown in Figs. 4 and 5. Furthermore, the sensitivity of the changes in vertical stress and horizontal stress of the roadway surrounding rock differed from each other, thereby showing that dynamic disturbance significantly affected the increase in horizontal stress of the roof and vertical stress of the sides. When the boundary conditions of the roadway varied, the response characteristics of the roadway surrounding rock exhibited considerable differences. The roof horizontal stress of the gob-side roadway was significantly larger than that of the solid-coal roadway. Moreover, the vertical stress of the section coal pillar along the gob-side roadway was under a state of stress concentration, which contributed more significantly to the risks of stability failure and rock burst than the solid-coal roadway under the disturbance.

\subsection{Displacement disturbance response analysis of the roadway surrounding rock}

As shown in Fig. 6, the surrounding rock deformation of different boundary conditions and parts of the roadway surrounding rock varied under dynamic disturbance.

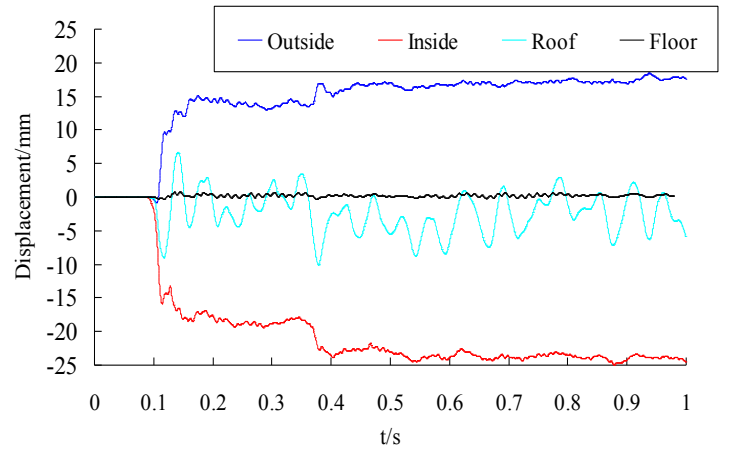

(a) Solid-coal roadway

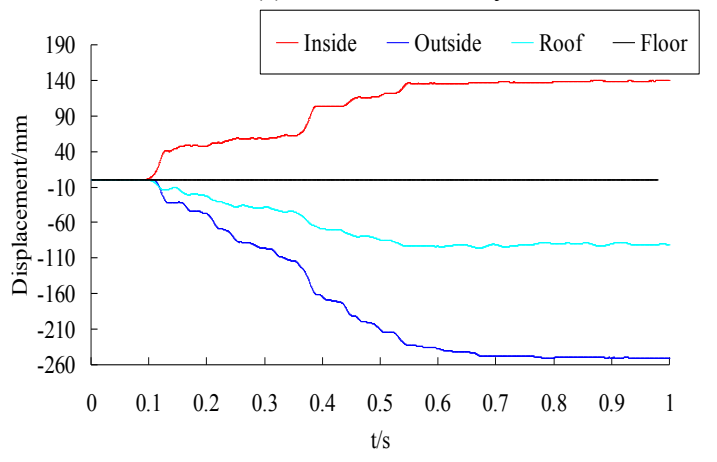

(b) Gob-side roadway

Fig. 6. Displacement response curve of the roadway surrounding rock

As shown in Fig. 6(a), for the gob-side roadway, the displacement of the inside was $24.54 \mathrm{~mm}$, which was slightly larger than that of the outside. The displacement of the roof changed constantly with small-amplitude vibrations. Meanwhile, the floor was in a relatively stable state, and displacement was not basically affected by disturbance. In general, the surrounding rock deformation of the solid-coal roadway is small, which is consistent with the stress level of the solid-coal roadway.

As shown in Fig. 6(b), for the gob-side roadway, the stress concentration degree of the roadway surrounding rock was high, which resulted in a larger convergence of the roof and the two sides. Under the dual influencing factors of stacked stress and poor stability of the coal pillar, the maximum convergence of the outside was $250.53 \mathrm{~mm}$, which could easily contribute to roadway caving and bolt instability. Although the wall caving of the inside was not as serious as that of the floor, the convergence of the inside also reached $139.58 \mathrm{~mm}$, and the risk of instability was present. The subsidence of the floor reached $91.81 \mathrm{~mm}$, and bed separation occurred, which could easily cause a roof caving accident. Accordingly, the support of the roof and the two sides of the gob-side roadway should be strengthened to increase shock resistance, and thus, avoid roadway instability and rock burst accidents caused by mine seismicity.

In conclusion, the convergence of the sides is considerably larger than that of the roof and the floor; the displacement reached a steady state after a disturbance of 0.6 s. The stability of the surrounding rock along the gob-side roadway was poor. The risk of rock burst increased significantly in the sides of the gob roadway under the disturbance.

\subsection{Verification of the engineering case}

The 10416 working face is covered by hard thick magmatite. Overburden stability is influenced by mining, and 
microseismic events will occur, thereby affecting the stability of the working face and the roadway. The Yangliu Coal Mine has introduced an SOS microseismic monitoring system, which can monitor the microseismic events of the entire mine. In the process of face mining, the roadway convergence monitoring points are arranged on the roadway, and the deformation of the roadway is monitored.

During the mining period of the 10416 working face, the seismic activity of the mine is strong, which exerts a certain influence on the stability of the mining roadway. Mine seismicity occurred 385 times during the mining period in November 2012. Fig. 8 shows the distribution planar graph of microseismic events, in which energy is equal to or greater than $10^{3} \mathrm{~J}$. As shown in Fig. 7, microseismic events are mainly concentrated at the center of the gob, which is formed by the mining of the 10416 working face near the 10414 gob side and above the adjacent gob. This result shows that the preceding simulation analysis is in accord with the actual situation on site.

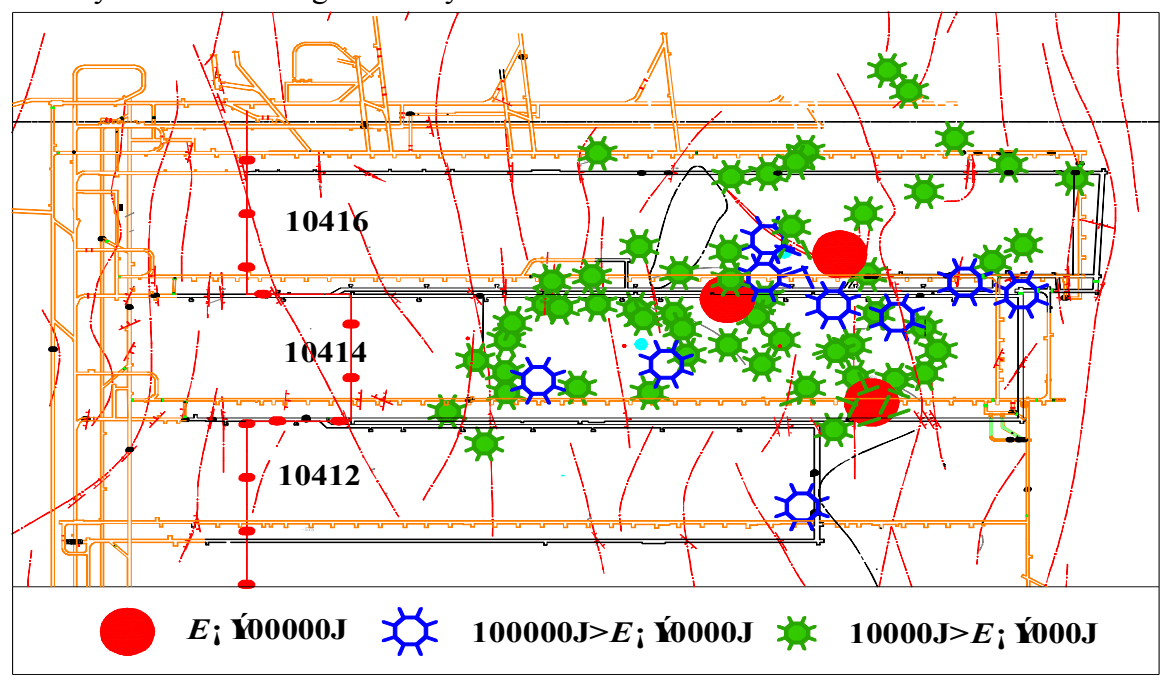

Fig. 7. Distribution planar graph of the microseismic events in Yangliu Coal Mine in November 2012

During the mining period in November, two monitoring points, which were used to record convergence of roadway deformation, were individually set on the wind lane (along the gob roadway) and the conveyor roadway $70 \mathrm{~m}$ ahead of the working face. Monitoring point $1^{\#}$ was used to monitor the wind lane, whereas monitoring point $2^{\#}$ was used to monitor the conveyor roadway. The convergence conditions for roadway deformation are shown in Fig. 8.

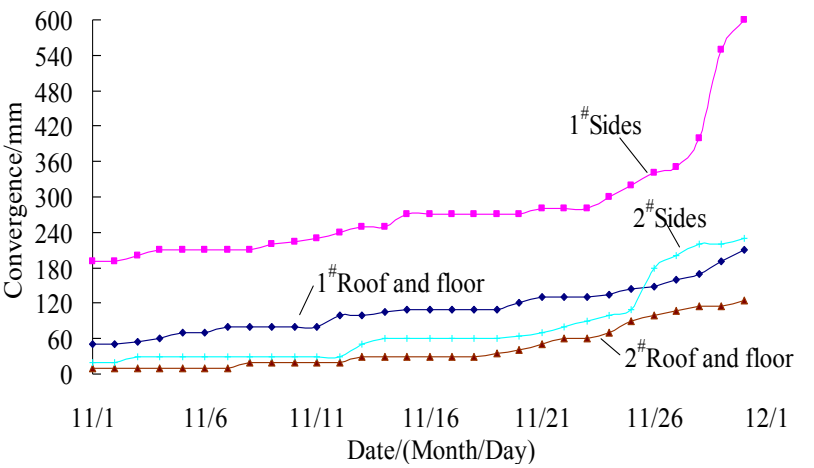

Fig .8. Convergence of the roof-floor and sides of the roadway

As shown in Fig. 8, the convergence of the two sides is larger than that of the roof and the floor. The convergence amplification of the two sides was large, whereas the convergence change of the roof was relatively flat, thereby indicating that the combined action of mine seismicity and mining-induced stress had a more evident effect on the sides of the roadway. This finding is consistent with the analysis result, which indicates that the deformation degree of the sides is larger than that of the roof and the floor under dynamic load disturbance.

\section{Conclusions}

To determine the influencing law of strong seismicity above a working face, a dynamic numerical analysis was conducted by applying shear stress waves on the bottom of the thick key layer. A case study on the gate-road stability of Yangliu Coal Mine in China was then performed. The conclusions drawn were as follows.

(1) The dynamic response sensitivities of the vertical stress and horizontal stress of the roadway surrounding rock differed from each other under strong seismic disturbance. This finding mainly showed that the dynamic disturbance significantly affected the change in horizontal stress of the roof and vertical stress of the sides. This situation would result in the spallation damage of the roof and the stress concentration of the sides. Meanwhile, the disturbance had no evident effect on floor stress level.

(2) Under mining seismicity, the horizontal stress of the roof and the vertical stress of the sides in the solid-coal roadway changed constantly with vibrations, whereas the horizontal stress of the sides and the vertical stress of the roof basically reached a steady state after a disturbance of $0.4 \mathrm{~s}$. The stress level of the inside was higher than that of the outside. The stress level of gob-side roadway was considerably higher than that of the solid-coal roadway. Roof horizontal stress was more apparent, which might contribute to the support instability of the roof. The stress level of the outside was higher than that of the inside. The coal pillars along the gob were under high stress state, and the possibility of instability was high.

(3) The significant influencing time of the disturbance on the displacement of the roadway surrounding rock is $0.6 \mathrm{~s}$, and the convergence of sides is larger than that of the roof and the floor. The convergence of the surrounding rock of the gob-side roadway is considerably larger than that of 
solid-coal roadway, and the stability of the roadway was poor. The deformation of the outside was significantly larger than that of the inside in the gob-side roadway, whereas the deformation of the inside was slightly larger than that of the outside in the solid-coal roadway. With a large deflection, bed separation easily occurred in the roof of the gob-side roadway.

This study can show the dynamic response process and the state of a roadway under strong seismicity. The dynamic response law of the stress and displacement of the roadway surrounding rock indicates that a high-strength anti-shear bolt should be used on the roof of the extraction roadway to strengthen the support. The pressure of the roadway sides should also be released at appropriate times to reduce the stress concentration level. However, the model is limited by special geological conditions and dynamic loading modes.
Further study is necessary to solve the dynamic response of the roadway under other loading modes.

\section{Acknowledgements}

This study was financially supported by the National Natural Science Foundation of China (No.51574155, No.51374139), Natural Science Foundation of Shandong Province (No.ZR2013EEM018), Scientific Research Innovation Team Support Plan of Shandong University of Science and Technology. Shandong University of Science and Technology graduate student science and Technology Innovation Fund Project (No.YC150307).

This is an Open Access article distributed under the terms of the Creative Commons Attribution Licence

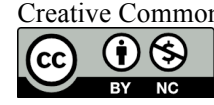

\section{References}

1. Liu Q. Z, "Study on sustainable use bearing capacity of coal resources in China". Journal of Shandong University of Science and Technology(Natural Science), 25(4), 2006, pp.87-89.

2. Jiang J. Q., ZHANG K Z, "Cause and control method of mine seismicity in fully mechanized top coal caving mining". Chinese Journal of Rock Mechanics and Engineering, 25(Sup 1), 2006, pp.3276-3282.

3. Zou D.Y., DUAN W., LIU Z.G., et al, "Study on mine earthquake induced by falling of overburden strata over goaf and its predictive technology". Journal of Shandong University of Science and Technology(Natural Science), 28(4), 2009, pp.54-58.

4. Wu L., Qian M., Wang J., "The influence of a thick hard rock stratum on underground mining subsidence". International Journal of Rock Mechanics \& Mining Sciences, 34(2), 1997, pp.341-344.

5. Wang W., Cheng Y. P., Wang H.F., et al, "Fracture failure analysis of hard-thick sandstone roof and its controlling effect on gas emission in underground ultra-thick coal extraction". Engineering Failure Analysis, 54, 2015, pp.150-162.

6. Wang W., Cheng Y.P., Wang H F, et al, "Coupled disaster-causing mechanisms of strata pressure behavior and abnormal gas emissions in underground coal extraction". Environmental Earth Sciences, 74(9), 2015, pp.1-19.

7. Boettcher M.S., Kane D.L., Mcgarr A., et al, "Moment tensors and other source parameters of mining-induced seismicitys in tautona mine, South Africa". Bulletin of the Seismological Society of America, 105(3), 2015, pp.1576-1593.

8. Farahani J.V., "Man-made major Hazards like seismicity or explosion; case study, Turkish mine explosion (13 May 2014)". Iranian Journal of Public Health, 43(10), 2014, pp.1444-1450.

9. Li D.Y., ZHANG K.Z., YU H.L., et al, "Research on the mine shock air-bump and anti-shock bulkhead". Journal of Shandong University of Science and Technology(Natural Science), 27(2) ,2008,pp.14-18.

10. Tiwari R.K., Chamoli A., "Is tidal forcing critical to trigger large Sumatra seismicitys?". Natural Hazards, 77(1), 2015, pp.65-74.

11. Gu S.T.,Wang C.Q.,Gu S.B., et al, "Study progress on identification and prediction of rock burst information in mines". Journal of Shandong University of Science and Technology(Natural Science), 30(2), 2011 ,pp.9-14.

12. Baumgardt D R, Leith W, "The kirovskiy explosion of september 29,1996:example of a ctb event notification for a routine mining blast”.Pure \& Applied Geophysics, 158(11), 2001 ,pp.2041-2058.
13. Zhu H., Liu P., Tong Z., "Numerical simulation research and application on protected layer pressure relief affection under different coal pillar width". Procedia Engineering, 84, 2014, pp.818-825.

14. Al-Abbas A.H., Naser J, Hussein E K, "Numerical simulation of brown coal combustion in a $550 \mathrm{MW}$ tangentially-fired furnace under different operating conditions". Fuel, 107(9), 2013, pp.688698.

15. Song X.X., ZUO Y.J.,ZHU W.C., "Effect of lateral pressure coefficients on pressure-released hole combined support with rockbolt under dynamic disturbance". Chinese Journal of Underground Space and Engineering, 9(5), 2013, pp.1076-1081.

16. Hu S.B.,WANG E.Y.,SHEN R.X., "Characteristics of dynamic disturbance response in deep coal and rock and its numerical analysis". Journal of China University of Mining \& Technology, 42(4), 2013, pp.540-546.

17. Abdul-Wahed M.K., Al Heib M., Senfaute G., "Mining-induced seismicity: Seismic measurement using multiplet approach and numerical modeling". International Journal of Coal Geology, 66(1), 2006, pp.137-147.

18. Liu J.K., Li C.W., Wang C.X., et al, "Spectral characteristics of micro-seismic signals obtained during the rupture of coal".Mining Science and Technology, 21(5) ,2011, pp.641-645.

19. Hosseini N., Oraee K., Shahriar K., et al, "Passive seismic velocity tomography and geostatistical simulation on longwall mining panel".Archives of mining sciences, 57(1), 2012, pp.139155.

20. Chen G.X., Dou L.M.,Gao M.S., et al, "Numerical simulation of dynamic vibration affecting rock burst in mining gateway caused by tremor".Journal of Mining \& Safety Engineering, 26(2) ,2009, pp.153-157.

21. Lu A.H.,YU S.L.,QIN H., et al, "Stability of layered crack structure in roadway surrounding rock under stress wave".Journal of China University of Mining \& Technology, 37(6), 2008, pp.769774.

22. Liu X.S., Zhang M., Ning J.G., et al, "Numerical simulatation on influencing factors of the developing height of water flowing fractured zone in shallow seams". Journal of Shandong University of Science and Technology(Natural Science), 31(5), 2012, pp.3136 .

23. Jiang L, Sainoki A, Mitri H S, et al, "Influence of fractureinduced weakening on coal mine gateroad stability". International Journal of Rock Mechanics \& Mining Sciences, 88, 2016, pp.307317. 